
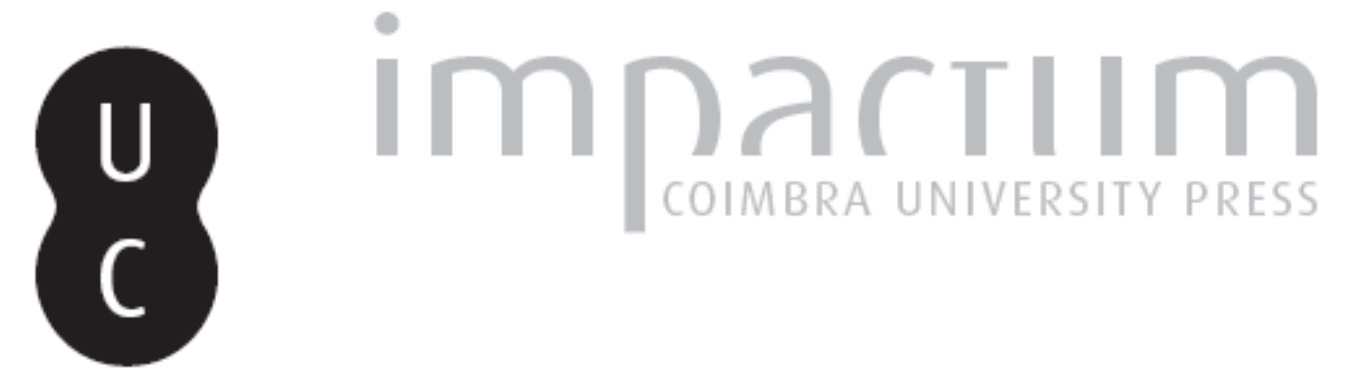

\title{
Imaginação e literatura
}

\section{Autor(es): $\quad$ Rodrigues, Ernesto}

Publicado por: Imprensa da Universidade de Coimbra

URL persistente:

URl:http://hdl.handle.net/10316.2/42583

DOI:

DOI:https://doi.org/10.14195/0870-8584_4_14

Accessed : $\quad$ 26-Apr-2023 11:41:41

A navegação consulta e descarregamento dos títulos inseridos nas Bibliotecas Digitais UC Digitalis, UC Pombalina e UC Impactum, pressupõem a aceitação plena e sem reservas dos Termos e Condições de Uso destas Bibliotecas Digitais, disponíveis em https://digitalis.uc.pt/pt-pt/termos.

Conforme exposto nos referidos Termos e Condições de Uso, o descarregamento de títulos de acesso restrito requer uma licença válida de autorização devendo o utilizador aceder ao(s) documento(s) a partir de um endereço de IP da instituição detentora da supramencionada licença.

Ao utilizador é apenas permitido o descarregamento para uso pessoal, pelo que o emprego do(s) título(s) descarregado(s) para outro fim, designadamente comercial, carece de autorização do respetivo autor ou editor da obra.

Na medida em que todas as obras da UC Digitalis se encontram protegidas pelo Código do Direito de Autor e Direitos Conexos e demais legislação aplicável, toda a cópia, parcial ou total, deste documento, nos casos em que é legalmente admitida, deverá conter ou fazer-se acompanhar por este aviso.

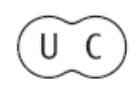




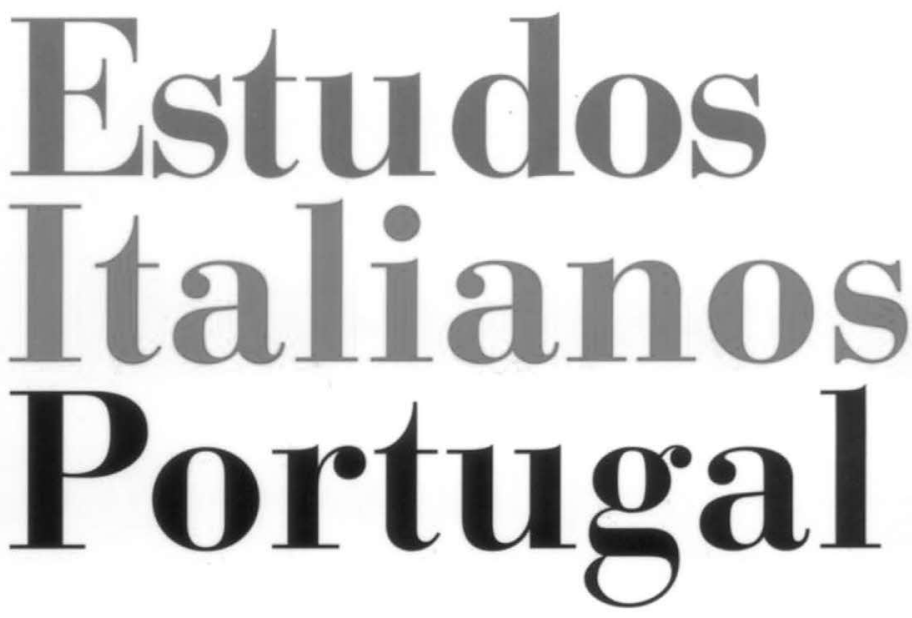

Instituto

Italiano

de Cultura

de Lisboa

Nova Série

$\mathbf{N}^{\mathbf{0}} 4$.

2009 


\section{IMAGINAÇÃO E LITERATURA}

ERNESTO RODRIGUES

Quinto volume da série Leonardo, Imaginação e Literatura recolhe as conferências do Quarto Encontro de Italianística realizado há um ano, em Coimbra. Raros termos calhavam melhor a Da Vinci que este de imaginação. Temos, nessa conformidade, recurso à Lua, sonhos e visões; mas, céus!, seria bem pouco. Ora, o assunto exige um método; e, como diz a coordenadora, Rita Marnoto, no mais longo texto - sobre literatura comparada -, que encerra, o método é tão importante quanto a matéria.

$\mathrm{Na}$ sua Introdução, lembra Rita Marnoto as "duas facetas da imaginação" segundo Jean Starobinski: "enquanto instrumento de conhecimento" na hipótese científica, na literatura e demais artes; "enquanto alma do mundo" (p. 5), ou via de eleição para a magia, o messianismo, a teosofia. As construções arquitectónicas - cidades, nomeadamente - são os casos mais flagrantes: inspirando-se em Piranesi e Escher, a escola de Harry Potter, Hogwarts, sintetiza essa dupla faceta.

A sintaxe da imaginação, em esquiva permanente ao cristalizado (a não ser que o tome por motivo), busca representar-se o que não existe ("qui n'est point", diz Descartes, em Les Passions de l'Âme [1649], art. 20), um visível tirado da experiência em crise. Com esta fórmula, significo o átimo criador, que recorre a lugares-comuns de um pensamento, desembocando em maneira, idiolecto, estilo. Esses loci, a par 
da referência, sem forçosamente coincidirem - se quero o topos do gigantismo, inabarcável, posso pensar, ou penar, em soluções babélicas, e, hoje, virtuais, como a nanotecnologia -, esses lugares-comuns, dizia, fundam processo: se, por exemplo, vamos a caminho da alegoria, uns preferem a imprevisibilidade serena de Calvino, outros a metralha discursiva de Saramago, e gostos discutem-se, na ordem dos críticos. Entenderão melhor, se transcrever o diário La Nación (15-I-2009), de Buenos Aires, sobre o penúltimo Saramago: "La ligereza del tono y la minuciosa descripción de los aprestos y avatares del viaje apelan a la simpatía condescendiente del lector y al ensueño que produce la travesía del animal mágico y bondadoso. Pero allí donde un Italo Calvino hubiese construido, a partir de un hecho absurdo o extraño, una portentosa y compleja reflexión sobre la conciencia de la civilización europea en una particular encrucijada histórica - como en la serie Nuestros antepasados -, Saramago elaboró en este caso un relato moralizante que haría las delicias de los estudios Disney, cuya popularidad y general beneplácito no interesa discutir aquí. Incluso cuando busca la ironía, su reiterada simpleza, que sólo podemos imaginar deliberada, tiene a menudo la sutileza del cartoon: [...] Escrito con un oficio de décadas para resolver el trámite narrativo, El viaje del elefante aguarda una mágica extrañeza que, salvo en algunos pasajes, nunca llega. Su melancólico logro tal vez consista en la fatal coincidencia entre el estilo del libro y su tema: escrito para ser venerable, de una buena fe paquidérmica, de lento andar y con una piadosa gracia que mal disimula su pesantez."

Quando arrazoados ofuscam a imagem, todos perdem. Em contrapartida, quando a sinestesia se abre, refrescada pelo olhar da manhã, temos o resto do dia para a celebrar. De facto, criamos presenças reais, estamos em processo, no Purgatório da criação (que só foi abolido na Teologia), segundo verso tão feliz aqui lembrado, que Borges ou Calvino apro- 
veitaram: "Poi piovve dentro a l'alta fantasia." Comungo da resumida leitura, que prevê a ideia de chuva-inspiração; e sublinho a "memória cultural" que nos circunscreve, e perfuma este dossiê. Nesse sentido, José Gomes Ferreira dirá: "Chove no som da sineta..." (Poema XXXVIII das "Heróicas" [1937, 1938, 1039], em Poesia - I, 5. ${ }^{a}$ ed., Lisboa, Portugália Editora, 1972, p. 153; terminando: “E, a pegar na borla, / um senhor de fraque / [...] / - segura na mão / a imaginação / dum ramo de rosas..." Analise quem quiser. Tentemos um balanço.

Abre Giulio Ferroni o primeiro apartado da tripartição, discorrendo sobre a geração de 1968 italiana. É um texto informativo e de síntese sobre autores de antes e após-68, como em Portugal ainda se não fez, nem que fosse tão-somente para os filhos da crise coimbrã de 1969. Lemos Ferroni e essa ausência agudiza-se, quando um Ruben A. já levara, em 1964, com $A$ Torre da Barbela, essa imaginação ao poder, e, cumes da Europa ressacada, Maina Mendes, de Maria Velho da Costa, e, sobretudo, A Noite e o Riso, de Nuno Bragança, sinalizavam, há precisamente 40 anos, viragem retomada em poucos. Ferroni mostra o cenário sessentista de negatividade, quer na "redução do eu", quer na "recusa dos mecanismos do consumo cultural" (p. 16), sobrevindo desse choque um "regresso à intimidade", que redundou, afinal, em "simples procura da felicidade pessoal, apenas se concentrando sobre a satisfação dos desejos e das ambições de cada um, e chegando a exaltar os interesses do individualismo, a capacidade de sucesso e a competitividade, no quadro de um consumismo agressivo e de um egoísmo de massas". Eis no que nos tornámos. Culturalmente - melhor, contraculturalmente, como então se preferia -, vimos assistindo a "um exibicionismo espectacular" (p. 18), animado por instituições e meios de comunicação carentes, que vedetizam de um dia para outro e pedem autobiografias a imber- 
bes de trinta anos. No caso português, muitas formas de libertação artística do 68 europeu - caso de leituras públicas e dos cantautores, da itinerância, outras modalidades de comunicação -, bem como "a obsessão pela política” (p. 19), que também se mostraria bloqueadora, só chegaram com o 25 de Abril; no campo do ensaio, todavia, intervalava-se, já, uma brisa de novidade, patente nos suplementos literários. Quando vemos os resultados, compreende-se a desilusão de Franco Fortini, ou do bom lusíada, que, para a década de 70, só lembre, daquela trindade, Silêncio para 4 (1973), Directa, Casas Pardas e, também em 1977, de Dinis Machado, O Que Diz Molero. Isto, porque Miguéis ou Sena são cilindrados pela vida em exílio. Sem o "magma da negatividade", que Ferroni vê para a literatura italiana pós-68 - de que o assassínio de Pasolini, em 1975, é representação suprema, poeta dialectal que acabava de se reeditar, refundido, em título também aproveitado por Rita Marnoto -, sem, duas gerações passadas, essa "forte tempestividade, na sua ligação ao presente" (p. 30), a literatura portuguesa cá vai, nem europeia, nem americana, não sabemos se nacional. Mas voltaremos aqui.

Este "país do inverosímil" está no título de Maria Luísa Malato Borralho, que estuda uma viagem à Lua de Manuel de Figueiredo na peça $A$ Grifaria (de 1777, segundo o "Prologo"). O alinhamento dos artigos vem de fora para dentro (de Itália para Portugal) e do século XVIII para a Idade Média. Começam por um excurso historiográfico e teórico, para assento e justificação do tema, com bibliografias diversas. Assim, Maria Luísa Borralho esclarece como, desde o século XVII até há 50 anos - sendo mais conhecidos Um Homem na Lua, de Edgar Allan Poe, e Da Terra à Lua, de Júlio Verne -, a ciência e a literatura se interessaram pela Lua. Acrescento ementas em atenção aos leitores.

A passarola de Bartolomeu de Gusmão elevada aos céus no Memorial do Convento saramaguiano foi menos ruidosa, 
creio, do que as subidas de Lunardi, cantado por Elmano, e, já em 1818, do "aeronauta" Robertson - ainda em Lisboa -, subida narrada por Júlio de Castilho' ${ }^{1}$. N'O Cosmorama Litterario (n. ${ }^{\circ} 10,7-$ III-1840) há "Uma Viagem ao Sol" que pode ser a primeira tentativa nacional de ficção científica. "Viagens à Lua", como intitula O Panorama, em 1852 (p. 56), seriam impossíveis, pela força da gravidade. Garrett, nas Viagens..., lembrara as "passarolas de Icaro" (cap. III) e as "estradas dos aereonautas" (cap. XIII), termo que discuti com Ofélia Paiva Monteiro, num almoço, em São Paulo, e não sei como virá na sua edição crítica, bem capaz de me estragar este efeito... De qualquer modo, não conheceria Garrett o francês aéronaute, desde 1784, ou o nosso aeronauta, já em 1836 no Novo Diccionario Critico e Etymologico da Lingua Portugueza, de Francisco Solano Constancio? Com ou sem gralha, saberia, também, que já se preferia o prefixo aero-, em vez do castelhano e italiano aereo-, como na palavra aerómetro, que encontro na Gazeta de Agricultura e Commercio de Portugal (Lisboa), em 1-IX-1813. Outras luas e balões estão em Júlio César Machado. Mas a ensaísta alarga o leque.

Mais interessante do que sair deste chão - afinal, "nada no enredo de $A$ Grifaria faz lembrar o Mundo da Lua" (p. 49) - é imaginar um país de grifos, meio águias, meio leões, tal como o Ruben A. de 1973 propõe um monstro de quatro patas e duas vozes versando o amor. Figueiredo é um artista de títulos, que, como bem sabem os editores, são mais importantes que o miolo. Daí, aquele parágrafo das Viagens na Minha Terra (cap. IX): "Poeta em anos de prosa! Oh Figueiredo, Figueiredo, que grande homem não foste tu, pois imaginaste este título que só ele em si é um volume! Há livros, e conheço muitos, que não deviam ter título, nem o título é nada neles." Depois, é um título novo, pois o

1 Memorias de Castilho, 2. ${ }^{\text {a }}$ ed., t. I, Coimbra, Imprensa da Universidade, 1926, p. 180-191 [180]. 
vocábulo falece nos dicionários: em si, o "monstrosinho" do grifo não espanta, se é caso de alegoria; já nos questiona, porém, se é um colectivo - grifaria -, e, neste colectivo ausente, se marca a importância (tratando-se de uma guerra dos sexos) da parte regularmente ausente que são as mulheres... A par de grifos e grifas, contudo, e lido 1777, quando morre D. José e encerra o consulado pombalino, tanto podemos falar, ainda, de um poder dividido, como, olhando ao bom neoclássico, entender uma política de grifas (do francês griffe), de garras, de rapina e unhas aduncas. Por outro lado, inspirar-se em Bosch não é pequeno achado em dramaturgo, "ademais dito árcade e neoclássico" (p. 37). Seria nas Tentações de Santo Antão, como se avança, dubitativamente?

No segmento teórico, a alínea "Verosimilhança e verdade" participa de um debate milenar, que, na terceira parte deste volume, Stefano Jossa, em "Literatura como ficção”, reavalia e sintetiza, a contento. Sabe bem reler Aristóteles (p. 40), para lhe criticarmos a Poética dos "impossíveis", que, diz ele, são um "erro", quando representados pelo Poeta. Mas, acrescenta, o "erro" é desculpável, "se atingiu a finalidade própria da poesia"... No que ficamos? Ficamos em que o Poeta representa, sempre, possíveis - não enquanto finalidade em si, mas por uma íntima e coerentemente articulada decisão, que já não é só verosímil ("o verosímil não passa da opinião da multidão" [p. 41], lê-se, corroborando Sócrates, no Fedro), mas a Verdade, que não é a verdade do Historiador. A liberdade de Figueiredo vai mais longe do que os cuidados de António Augusto Teixeira de Vasconcelos, ao anunciar, em folhetim d'A Revolução de Setembro (em 5-IX-1862), D. Jaime ou a Dominação de Castela. De início, nada de estranho: "Este seculo é essencialmente amigo da verdade. Admitte a ficção mas verosimil, quer que o divirtam e que o distraiam, embora seja com mentiras com tanto que elle as possa julgar possiveis, [...]." Stefano Jossa defenderá essa poética da mentira. Mas, a seguir, não falta em Teixeira de Vasconcelos uma 
unção de "moral", que pode deitar tudo a perder: "Graças á época em que nasceu e se creou, coube-lhe [a Tomás Ribeiro] na disposição de entrecho do seu poema plena liberdade, unicamente limitada pelas severas leis da claresa, da verosimilhança, da verdade e da moral. [...] A verosimilhança da invenção é manifesta e habilmente sustentada pela inalteravel verdade dos caracteres. [...] É licito crear, em poemas e romances caracteres inteiriços, no bem e no mal, porém esta liberdade convém usar-se com parcimonia para que os leitores não menosprezem o enredo por inverosimil [...]." Esta "parcimónia" era um quisto há muito arrancado por várias formas de imaginação; lembra o uso do plural "liberdades" após Abril por quem defendia uma liberdade... descartável.

Uma dessas formas de imaginação, em clave onírica, subsiste na épica de Camões e Tasso, confrontados por Manuel Ferro à luz do sonho de D. Manuel n'Os Lusíadas, c. IV: 67-75 - afim do sexto sonho de Jerusalém Libertada, ambos, D. Manuel e Godofredo, transportados a um ponto alto do firmamento -, que historia polémica de Manuel Pires de Almeida (1629) a José Agostinho de Macedo (1820). É o mais largo em notas de rodapé, de modo a iluminar aquele e seus contendores: João Soares de Brito, João Franco Barreto, Manuel de Faria e Sousa, António de Melo da Fonseca (aliás, José de Macedo); mas servem, também, para bibliografar a noção de 'sonho'.

Informando quanto acabei de defender, abre com o De Anima aristotélico, domiciliando a imaginação "no nosso poder de decisão" (p. 53), ou seja, como também se retomará em Ana Maria Machado, estamos na "imaginação deliberativa" (p. 100). Manuel Ferro cita, depois, o verbete de Voltaire na Encyclopédie, segundo o qual as percepções entram pelos sentidos, e "la mémoire les rétient, l'imagination les compose". Qual “dom divino”, teríamos, pois, a imaginação passiva, retendo as imagens dos objectos (mas, neste caso, 
em que se distingue da memória?), e a activa, pela reorganização a que procede e sua projecção "no reino dos sonhos, distorcendo a representação do real" (p. 54). Eu diria: projectando-se, também, no reino dos sonhos, mas não só; mais: sem forçosa distorção do real, ou sua representação.

Face ao incómodo de não ver na imaginação passiva mais do que simples memória, e talvez nem se justificar qualificá-la, tende-se, actualmente, para o equilíbrio entre "mémoire affective et immagination", alínea de um balanço a quatro mãos e disciplinas fraternizando cada vez mais, quais sejam o ensaísmo literário e as neurociências, na assinatura dos irmãos Jean-Yves \& Marc Tadié, em Le sens de la mémoire (Paris, Gallimard, 1999). Imaginar é, então, rever por obra e graça de afectos; é modificar as nossas memórias; em suma, somos imaginações - tantas delas induzidas, sobretudo, quando em dor.

Enquanto "estratégia" de "precognição do futuro", o sonho épico é prolepse, tal como a imaginação, pois nos re-situamos no que já não somos olhando para um presente resolvido, e futuramos mundos donde nos vemos, estando a criá-los. Curiosamente, dir-nos-á Ana Maria Machado, "No mundo hebraico, uma das palavras para traduzir o sentido de imaginação era justamente yetser que tem a mesma raiz que yetsirah com o significado criar" (p. 99). A afecção da memória é pura imaginação; aquela só retém o que esta consente. Ou seja, a memória é pura virtualidade, uma função. Daí que razões políticas, de escola, retóricas ou pedagógicas (até ao Castilho de 1862 propondo a substituição escolar de Camões por Tomás Ribeiro) - distraídas pelo uso da mitologia, verosimilhança, necessidade, imitação, decoro, conveniência e invenção (p. 62) - sejam do foro afectivo, a favor ou contra.

Descendo no tempo, os quarto e quinto ensaios da primeira parte dirigem-se à Idade Média. Daniela di Pasquale busca as "possibili fonti dantesche" (p. 85-86) no Boosco Deleytoso (impresso em 1513), em cinquenta por cento dos 
capítulos tradução ou adaptação do De Vita Solitaria de Petrarca, também personagem. Resumidamente, funcionam por oposição, citação implícita e convite aos loci communes da Commedia. Opõe-se na deleitação que se tira do bosque, termo este que, na Commedia, vira locus horribilis, pois "ha sempre valenza negativa di ambientazione infernale cupa e spaventosa" (p. 90); implicita "il motivo dello smarrimento nel bosco e della compagnia di una guida" (p. 93); lembra vários versos, aqui anotados.

Do Flos Sanctorum em lingoagi português (1513), que traduz a Legenda Aurea de Voragine - Fernando-António Almeida fez uma adaptação em Vidas Maravilhosas de Antigos Santos (Lisboa, Teorema, 2005) -, tira Ana Maria Machado três exemplos para mostrar "o imaginário da salvação" (p. 99) numa era de indefinição de fronteiras entre "visível-invisível, natural-sobrenatural, este mundo e o Além” (p. 117). Explicitara-se, previamente - e para obviar à fácil associação de sobrenatural e miraculoso no maravilhoso cristão -, tripartição de Jacques Le Goff em "mirabilis, de origem pré-cristã, magicus, a deslizar para o sobrenatural maléfico, e miraculosus, o sobrenatural cristão" (p. 102), comungando cada um deles desse "traço nuclear do maravilhoso" (p. 103) que é a imprevisibilidade, seguida de uma geral naturalização, inclusive, do transcendente. Antes ainda, convocada a "imaginação deliberativa" do De Anima, chamara a ensaísta Avicena, que distingue "entre a imaginação compositiva (imaginativa) e a imaginação retentora (phantasiae), duas das cinco potências da alma que Tomás de Aquino refere na Suma teológica" (p. 100).

Concebo, em resumo, a deliberativa (faculdade que distingue os homens dos animais, como quer Aristóteles, mas também homens de homens) e a compositiva, desejavelmente activa, inovadora e arriscada, indiferente àquela "maginaçom" que, não assente na mais "pequena certidom", maravilhava negativamente o infante D. Henrique, segundo a Chronica 
do Descobrimento e Conquista de Guiné, de Zurara². Medieva e latinamente considerada "imaginação retentora" - a que pudéramos reduzir a memória -, phantasia fora, outrossim, o termo grego de imaginação, lembra Maria Luísa Malato Borralho (p. 36). Ora, tomando eu fantasia por modulação da imaginação, não sairá esta cumulada na alta fantasia de Dante? Ou essa alta fantasia significava, definitivamente, Imaginação?

No apartado 2, 'Didáctica do Italiano', não estranharemos que os estudantes de língua, em Coimbra, sejam de uma inventiva lexical por vezes divertida, à luz dos resultados de Alberto Sismondini. Passámos todos por isso, e até pode ser estilisticamente útil deitar uma personagem - portuguesa num colchão mórbido. No meu romance Torre de Dona Chama (1994, p. 236), um dos vinte burros que saem na ciganada da Festa dos Caretos tem esta nomeada e respectiva explicação: "Burro Mio! Exclamava dona Vernácula, que, antes da emigração para as línguas da Europa, era a única no sítio a falar italiano. Olhada com devoção, acordavam-se todos frente ao ecrã que sim, senhora, aquilo não era língua de gato, mas "transalpina" [...]. Dona Vernácula recolhera em casa bárbaros austríacos - bárbaros por mor da glote - que, petiscando o seu italiano, confundiram as bases fundamentais da senhora. Murmurou-se. De novo só, teve as naturais dificuldades de adaptação ao meio, com meter água em cada frase, dormindo em mórbidos colchões, comendo pato de guerra, cariciando il burro! Uma noite, na Feliza, por azar, a meio da prática sobre as mamas de Gina Lollobrigida e Claudia Cardinale, disse o professor que ele, sim, era homem de lhas untar, a ambas, devagarinho, com pomada de burro. Fez-se escândalo antes de luz; então, como ludíbrio de décadas que numa chispa

2 = Crónica da Guiné, ed. da Agência Geral das Colónias, 1949, p. 54. Maginação falta nos dicionários, que, todavia, podem trazer o arcaísmo maginar. 
se revela, saltou de riso em riso a boa-nova e dona Vernácula, ofendidíssima, fez gramática seu livro de cabeceira e nela se encontrará em breve folha lancelada ensombrando a etimologia."

Antes de Sismondini, Lino Mioni, com experiência docente de Conservatório, educa-nos em pronúncia, no "famoso quadrilátero do sistema vocálico do italiano” (p. 128), pensando nos estudantes de canto lírico. Os informes sobre docência arrepiam: com o italiano ausente de cursos superiores de canto e de ensino, permite-se que "um licenciado em canto via ensino seja professor de canto lírico sem conhecimento de italiano e, talvez pior do que isso, ensine a cantar o repertório nesta língua" (p. 124). O mesmo para o francês e alemão.

A terceira parte do volume versa "Questões Teóricas". Em "Literatura como ficção", Stefano Jossa responde ao seguinte: "O que é que a literatura conhece, e como o conhece? É tão-só um jogo, uma arte que produz beleza, mas não tem nada a ver com o mundo, como queria Croce, ou é uma forma de empenho que nos permite intervir na realidade e mudá-la, como queriam os escritores neo-realistas? Enfim, pode sair-se desta contraposição?" (p. 149) Velhas e novas questões. De Dante às imaginações de Boccaccio, de Teófilo Folengo a Orlando Furioso - "Não sabemos se Ariosto conhecia o Baldus" (p. 155), diz Stefano Jossa: creio que sim, por força do comum Turpim, convergindo, depois, em Fastigínia, de Tomé Pinheiro da Veiga -, conclui o ensaísta: "Apesar de o que [Ariosto] conta parecer incrível, quem é capaz de ver claro "il lume del discorso" conseguirá reconhecer a verdade.” (p. 157) Seja, a mentira não é falsidade, mas forma de conhecimento; a História tornou-se uma ficção controlada.

O balanço mais actual sobre literatura comparada encerra o volume. Há a parte dos factos, diacronia, teorização e um 
final-surpresa. A disciplina está na moda, mas um poço, ainda, de distracções, e logo do lado italiano (p. 169). A questão do 'nacional' - prometi voltar aqui - dir-se-ia transcendida, porque, efectivamente, há “zonas de interacção que tornam artificial qualquer tentativa de delimitação de campo com barreiras estanques" (p. 171). Mas, se já existem fronteiras, embora franqueáveis, alguma razão haverá, como dentro de alguns territórios se destaca um provincianismo, quiçá “mancha dialectal" (p. 172). E as fronteiras de uma língua são mais complexas. Após Goethe, houve alguns sonhos de uma literatura europeia, mesmo universal, que jamais poderiam eximir-se à relação entre uno e diverso, para saudar Claudio Guillén, ou à fundamental "indagação" (p. 177) comparatista. Exemplos desse apelo estão na "anthologie critique et commentée" de Yves Hersant e Fabienne Durand-Bogaert, Europes. De l'Antiquité au XXe Siècle (Paris, Robert Laffont, 2 000), antologia plural, mas limitada, no próprio desconhecimento de parte da nova Europa literária, que pudera ter maior presença, antes da adesão política de 2004. Saliento artigo de Giuseppe Mazzini, de 1829, em que se defende uma literatura europeia (p. 139-146), extraído do seu Saggio sopra alcune tendenze della letteratura europea nel secolo XIX.

Percorrido caminho hermenêutico e da teoria da recepção, e assente que nem tudo é cultura (p. 185; a culturologia fez-se temível, é um facto), o conceito de "locação", provindo dos estudos culturais, é o desafio para, do simbiótico em que misturarmos língua, nação, cultura, se chegar a uma sempre hesitante, mas alargada, identidade, no exílio da condição intelectual. Exílio terrestre, não nacional, corrobora a nossa ensaísta - o que tem efeitos benéficos, se isento de preconceitos; mas será assim tão simples, vistos aqueles ingredientes de língua, nação, cultura?

A surpresa está na "convergência entre filologia, crítica de fontes e literatura comparada" (p. 187), apoiada em "marcas de fábrica" (p. 188; sinais que tanto interessam aos estudos 
culturais), no estudo da interdiscursividade (que Cesare Segre soube distinguir da intertextualidade, ou "enunciados sem assinatura") e na "circulação de temas, formas e estilemas", bem como no "modo como se geram mecanismos de articulação entre textos e quadros histórico-culturais, diluindo a rigidez de fronteiras nacionais, linguísticas e até geográficas" (p. 187). Diluindo a rigidez, sim, de várias fronteiras.

Daí que, jogando com a Vita Nova e Benigni (um Roberto Benigni descendente da Itália 68, leitor público da Commedia), a confirmação final sobre o entendimento de literatura comparada venha em interrogação retórica: "Uma nova filologia?" (p. 191)

Por mim, lembrado da fórmula tão ingénua como produtiva 'literatura de imaginação', desejaria que os nossos domínios de estudo assentassem numa filologia da imaginação. 